\title{
Eating and weight concerns among Sikkimese adolescent girls and their biocultural correlates: an exploratory study
}

\author{
Shailendra K Mishra and Susmita Mukhopadhyay* \\ Biological Anthropology Unit, Indian Statistical Institute, 203 Barrackpore Trunk Road, Kolkata 700108, India
}

Submitted 16 May 2010: Accepted 13 July 2010: First published online 21 September 2010

\begin{abstract}
Objectives: Growing concern about ideal body image among adolescent girls in developing countries has led them to follow dietary modifications. In general, the ideal body image is perceived as a 'thin body' and now tagged with the concept of being physically fit. The present study evaluates the prevalence of weight concerns, and subsequent eating behaviour modifications among a group of adolescent girls in Sikkim.

Design: Pre-tested FFQ and dietary behaviour questionnaire were canvassed through direct interviews. Anthropometric measurements were taken following standard techniques. In the present study, dieting stands for skipping meals or avoiding certain food items.

Setting: Sikkim, India.

Subjects: A total of 577 girls were selected from several blocks of all four districts of Sikkim.

Results: The results of the study show that concern with weight reduction is growing among adolescent girls, particularly among urban girls of affluent families. Girls from families with a higher economic status are about two times more likely to report dissatisfaction with their body weight $(\mathrm{OR}=1 \cdot 96 ; P \leq 0 \cdot 05)$ and these girls are five times more likely to report the need for dieting.

Conclusions: It is evident that weight concern and dissatisfaction over body weight are growing among adolescents. It can be safely argued that eating disorder, once a problem of the Western world, is now slowly creeping in among adolescents of the developing world as a consequence of rapid lifestyle changes over the past few decades.
\end{abstract}

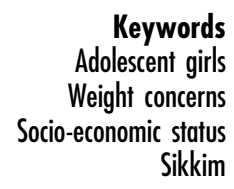

Keywords

Adolescent girls Socio-economic status Sikkim
Adolescent girls in today's society are extremely conscious of perceptions of a perfect body. With the growing sense of ideal body image during adolescence, they try to lose or gain body weight to attain the perfect body ${ }^{(1)}$. Various prospective and cross-sectional studies have identified that several factors such as age, gender, frequent dieting, preoccupation with thinness, being teased about body shape or size, personal dissatisfaction over body weight, perceived peer and media pressure to be thin and family history of an eating disorder are important in determining eating behaviours and weight concerns among adolescents ${ }^{(2-5)}$. Moreover, modernized societies tend to value thinness and socially discriminate against overweight individuals $^{(1)}$.

Population-based studies generally suggest that young children are rarely concerned with their weight and body shape ${ }^{(6,7)}$. A few longitudinal studies indicate that such concerns develop with the onset of adolescence and become more pronounced by late adolescence ${ }^{(8,9)}$. Further, there remains a link between weight perception, body image and cognitive development among adolescents ${ }^{(2)}$.
Previous studies have attempted to understand the factors responsible for the development of dissatisfaction related to weight and the corresponding dietary modifications among adolescents as within the context of and as a direct consequence of rapid lifestyle changes in the recent past $^{(10,11)}$. As observed, food composition affects energy balance by influencing satiety, hunger, food acceptance and metabolism. Yet, long-term food restraints and dieting can adversely affect normal growth and development, including reproductive maturation, skeletal growth and physical functions ${ }^{(12)}$. Adolescents are often influenced by the media because of their low cognitive maturity and over-simplistic analysis of media messages ${ }^{(13,14)}$. Dieting is a poorly defined behaviour having differing meanings for both patients and professionals. Overall, it suggests an intentional, often temporary change in eating habits to achieve weight loss ${ }^{(15-17)}$. The dietary pattern of a population is governed by many factors such as geography of the region, socio-economic and cultural characteristics of the people and their exposure to the world outside $^{(14)}$. 
In India, similar problems have now become conspicuous and are reported in a study by Chug and Puri ${ }^{(18)}$ in Delhi. This research shows that approximately $50 \%$ of the teenage girls in the study population were following a diet that could easily be considered as a 'starvation diet', leading to various nutrient deficiencies, hormonal imbalance and sometimes amenorrhoea (cessation of menstruation). A study by Sadana et al. ${ }^{(19)}$ showed that in two cities in Punjab more than $70 \%$ of adolescent girls consumed fast foods between meals, hence reducing their appetite for regular meals.

The present study was carried out in Sikkim, a small mountainous state in north-east India, whose inhabitants are currently experiencing a major socio-cultural change due to influences associated with rapid urbanization and modernization processes. In general, over-concern with body image and shape can lead to restrictive dieting and unhealthy weight control measures, which may lead to potentially dangerous disordered eating behaviours ${ }^{(20)}$. The study investigates the level of dissatisfaction with body weight and subsequent actions taken by adolescent girls in terms of their perceived desire to diet (henceforth referred to as 'urge for dieting') and modify their food habits to reduce body weight and to become thinner. The study also investigates association between eating and weight concerns and the sociodemographic characteristics of these girls.

\section{Materials and methods}

\section{Study area}

The present study was conducted in Sikkim, a mountainous state of north-eastern India. The selection of participants was made from all the four districts of the state, i.e. North, East, West and South. Rural study blocks were selected mostly from North, West and South districts, whereas urban study blocks were selected from East district only, particularly in and around the State capital, Gangtok. Rural blocks situated within a $5 \mathrm{~km}$ radius from district headquarters, i.e. having better accessibility to the facilities available in a district town, were marked as suburban study blocks. The study participants in the rural areas were distributed in randomly selected revenue blocks (cluster of one or more villages) of the districts. In Gangtok, all the urban frame survey blocks (UFS blocks) marked by the National Sample Survey Organization were considered for the present study.

\section{Study population}

The current study included 577 girls (101 married and 476 unmarried) aged 15-19 years, from all three population subgroups of the state, i.e. Nepalese (caste group), Bhutias and Lepchas (government-defined scheduled tribes). These groups differ ethnically from one another but have shared a similar physical and social environment for several generations. The participants were mostly literate $(98 \cdot 2 \%)$ with variations at the level of education. They belonged to different social and economic strata and were of different religious communities (Hindu, Buddhist and Christian). A few differences did exist among them in terms of certain micro-cultural factors, yet they were not so conspicuous as to influence their day-to-day lifestyle.

Food habits in Sikkim are predominantly non-vegetarian (include egg, meat and often fish) with rice as the staple food. Both fresh and fermented meats are consumed ${ }^{(21)}$. With the promotion of tourism, a significant change in lifestyle and food habits has occurred during the past few decades, most conspicuously among children and adolescents.

\section{Sampling design}

The state of Sikkim consists of 453 revenue blocks (administrative units consisting of few villages), of which $15 \%$ were selected randomly for the present study. A twostage sampling design was used in selecting the study participants. At the first stage all married and unmarried adolescent girls from these selected blocks were enlisted by visiting each household in each selected revenue block. In the second stage, only unmarried girls were randomly selected from the list in proportion to their number in a particular block. At least $60 \%$ of the girls from the complete list of girls in a particular block were considered. In all, sixty rural and fifteen suburban blocks were selected. In the case of the urban sample, unmarried girls were selected from all eighty UFS blocks in Gangtok, in proportion to their number in a particular block. Since the number of married girls was much less compared to unmarried ones, all married girls willing to participate in the study were included and no sampling method was followed in selecting them.

\section{Data}

Data were collected on sociodemographic characteristics, food habits and dietary behaviours using intervieweradministered questionnaires in the household of each participant.

\section{Sociodemographic factors}

Sociodemographic data include age, marital and school enrolment status, level of education, place of residence of participants, along with household economic status (reported monthly family expenditure). The girls were divided into two age cohorts, i.e. younger adolescents (15-17 years) and older adolescents (18-19 years). The girls were grouped into four categories based on amount of monthly expenditure of the family, and into three groups according to their place of residence, i.e. rural, suburban and urban.

\section{Food habits and dietary behaviour}

Data on food habits were collected using a questionnaire with fifty-six major food items. Responses were recorded based on how often each of these foods was consumed (ranging from 'never or less than once a month' to 'three or more times a day'). The participants were asked to 
record the frequency of consumption of those major food items along with the dietary modifications practised to reduce body weight. Girls who either skipped meals once per week or avoided specific food items (high-energy foods) in their regular diet to reduce body weight have been categorized as showing 'urge for dieting'. Data were also collected regarding their satisfaction and dissatisfaction with their own body weight.

In general, questionnaires used in the present study had multiple-answer questions specifically prepared taking into consideration the cultural appropriateness of the contents. Cronbach's $\alpha$ was calculated $(>0 \cdot 8)$ to check internal consistency.

Interviews were conducted in private rooms by local female interviewers to avoid possible interference or reluctance in answering. Before beginning the survey, these interviewers were trained in the administration of this questionnaire. Written consent of participants as well as their guardians was obtained before beginning the interview. Protocols and measures used in the study were reviewed and approved by the Institutional Review Board of the Indian Statistical Institute.

\section{Antbropometric measurements}

Height and weight of the participants were measured and BMI was calculated for all participants. Waist and hip circumferences were measured for each participant in standing position using a fibreglass tape. Skinfold thicknesses were measured at three sites, i.e. biceps, triceps and subscapular, and the sum of skinfolds was calculated. All anthropometric measurements were taken following standard methods ${ }^{(22)}$ by a single trained individual.

\section{Statistical analysis}

Descriptive statistics are used to describe the sociodemographic characteristics of the study population. Consumption patterns of food items were derived using principal component analysis (factor analysis) and varimax rotation entering data from the FFQ, which includes fifty-six items. Frequency of consumption of these items was converted into daily equivalent frequencies and was entered into the principal component analysis. Most of the items were retained as they appeared in the FFQ to reduce the possibility of subjective decision bias in determining consumption patterns ${ }^{(23)}$. A few food items were not included in the principal component analysis due to very low frequency of consumption, such as smoked meat and certain fermented food items. Likewise, a small number of food items were grouped together if they represented similar foods in different forms such as 'churpi' and butter, both are prepared from fermented milk. Log-transformation was performed to reduce skewness and kurtosis substantially. The number of food groups identified was based on eigenvalues of more than $1 \cdot 30^{(24)}$. These food groups were represented by the factors (principal components) based on a breakpoint in the scree plot and interpretability. The items were considered to load on a factor if they showed an absolute correlation of $\geq 0.3$ with it and were retained for calculating food group scores. Inclusion of these items ensures that the food is more strongly related to the respective factors ${ }^{(25)}$. Inter-item reliability for each factor was assessed by Cronbach's $\alpha$ coefficient. Food group scores were calculated using the frequency of consumption of each food item and its weight determined by the factor analysis. Food group scores were categorized into tertiles on the basis of their increasing values. Association between food groups and sociodemographic variables was shown by $\chi^{2}$ values. Logistic regression models were fitted to estimate the association between participants' feelings of dissatisfaction over their body weight and subsequent urge for dieting and sociodemographic characteristics. All statistical analyses were carried out using the Statistical Package for Social Sciences statistical software package version $11 \cdot 0 \cdot 1$ (SPSS Inc., Chicago, IL, USA).

\section{Results}

Table 1 shows that the incidence of illiteracy was significantly higher in rural compared to suburban and urban areas. Urban participants generally belonged to families with higher monthly expenditure, compared to their suburban and rural counterparts.

The number of food groups identified through principal component analysis is categorized as 'vegetable-fruit-milkcereals', 'meat-fish-egg' and 'snacks-ice cream-beverages'.

Table 2 shows that a significantly higher percentage of younger adolescents ( $<18$ years) had higher scores for 'snacks-ice cream-beverages' compared to older girls ( $\geq 18$ years). However, more married girls, irrespective of their age, showed significantly lower scores for the same food group than their unmarried counterparts. Positive associations were observed between a high score for 'snacks-ice cream-beverages' and factors like urban living, school enrolment, higher economic status. For other food groups, i.e. 'vegetable-fruit-milk-cereals' and 'meat-fish-egg', not much variation in scores was observed for sociodemographic factors except for a direct association between economic status and the 'vegetablefruit-milk-cereals' food group. A large proportion of the girls belonging to families with a monthly expenditure of either less than Rs 2000 or greater than Rs 8000 showed higher scores for 'vegetable-fruit-milk-cereals' compared to the girls of other economic groups. A directional trend has not been found in the present study between economic status and food groups. The value of Cronbach's $\alpha$ was $>0 \cdot 8$ for all the three food groups indicating high inter-item reliability.

Table 3 shows dietary behaviours and concerns for body weight among adolescents by place of residence. Girls from urban areas differed significantly from their 
Table 1 Sociodemographic characteristics (\%) of the participants

\begin{tabular}{|c|c|c|c|c|c|}
\hline Variables & Rural (n 305) & Suburban $(n 76)$ & Urban $(n$ 196) & $\chi^{2}$ value & Total $(n 577)$ \\
\hline \multicolumn{6}{|l|}{ Age group } \\
\hline Younger adolescents ( $<18$ years) & $46 \cdot 33$ & $59 \cdot 78$ & $59 \cdot 78$ & \multirow[t]{2}{*}{$3 \cdot 34$} & $51 \cdot 05$ \\
\hline Older adolescents ( $\geq 18$ years) & $53 \cdot 67$ & $40 \cdot 23$ & $40 \cdot 23$ & & $48 \cdot 95$ \\
\hline \multicolumn{6}{|l|}{ Marital status } \\
\hline Married & $27 \cdot 08$ & $10 \cdot 77$ & $5 \cdot 63$ & \multirow[t]{2}{*}{$84 \cdot 41^{\star \star}$} & $17 \cdot 26$ \\
\hline Unmarried & $72 \cdot 92$ & $89 \cdot 23$ & $94 \cdot 37$ & & $82 \cdot 74$ \\
\hline \multicolumn{6}{|l|}{ Literacy status } \\
\hline Non-literate & 3.59 & $1 \cdot 15$ & $1 \cdot 34$ & \multirow[t]{2}{*}{$7 \cdot 19^{\star}$} & $2 \cdot 41$ \\
\hline Literate & $96 \cdot 41$ & $98 \cdot 85$ & $98 \cdot 66$ & & $97 \cdot 59$ \\
\hline \multicolumn{6}{|l|}{ Currently enroled in school } \\
\hline No & $44 \cdot 86$ & $19 \cdot 23$ & $15 \cdot 55$ & \multirow[t]{2}{*}{$114 \cdot 02^{\star \star}$} & $30 \cdot 74$ \\
\hline Yes & $55 \cdot 14$ & $80 \cdot 77$ & $84 \cdot 45$ & & $69 \cdot 26$ \\
\hline \multicolumn{6}{|l|}{ Monthly expenditure of the family } \\
\hline$\leq 2000 \mathrm{Rs}$ & $66 \cdot 72$ & $41 \cdot 54$ & $9 \cdot 65$ & \multirow[t]{4}{*}{$401 \cdot 45^{\star \star}$} & $44 \cdot 38$ \\
\hline 2001-5000 Rs & $23 \cdot 33$ & $41 \cdot 54$ & $35 \cdot 12$ & & $30 \cdot 66$ \\
\hline $5001-8000 \mathrm{Rs}$ & $6 \cdot 85$ & $12 \cdot 31$ & $30 \cdot 03$ & & $14 \cdot 93$ \\
\hline$>8000 \mathrm{Rs}$ & $3 \cdot 10$ & $4 \cdot 62$ & $25 \cdot 20$ & & $10 \cdot 03$ \\
\hline
\end{tabular}

${ }^{*} P$ value $<0.05$ level; ${ }^{* *} P$ value $<0.01$ level.

Table 2 Sociodemographic characteristics and urge for dieting (\%) among participants according to tertile of food group score

\begin{tabular}{|c|c|c|c|c|c|c|c|c|c|}
\hline \multirow[b]{2}{*}{ Characteristics } & \multicolumn{3}{|c|}{ Vegetable-fruit-milk-cereals } & \multicolumn{3}{|c|}{ Meat-fish-egg } & \multicolumn{3}{|c|}{ Snacks-ice cream-beverages } \\
\hline & T1 & $\mathrm{T} 2$ & T3 & T1 & T2 & T3 & $\mathrm{T} 1$ & T2 & T3 \\
\hline \multicolumn{10}{|l|}{ Age group } \\
\hline Younger adolescents & $35 \cdot 92$ & $32 \cdot 36$ & $31 \cdot 72$ & $42 \cdot 07$ & $21 \cdot 04$ & $36 \cdot 89$ & $14 \cdot 89$ & $58 \cdot 90$ & $26 \cdot 21^{\star *}$ \\
\hline Older adolescents & $34 \cdot 82$ & $33 \cdot 60$ & 31.58 & $48 \cdot 58$ & $15 \cdot 38$ & 36.04 & $17 \cdot 41$ & $65 \cdot 18$ & $17 \cdot 41$ \\
\hline \multicolumn{10}{|l|}{ Marital status } \\
\hline Married & $30 \cdot 70$ & $35 \cdot 09$ & $34 \cdot 21$ & $38 \cdot 60$ & $19 \cdot 30$ & $42 \cdot 10$ & $27 \cdot 19$ & $65 \cdot 79$ & $7 \cdot 02^{\star *}$ \\
\hline Unmarried & $36 \cdot 65$ & $32 \cdot 35$ & 31.00 & $46 \cdot 60$ & $18 \cdot 33$ & 35.07 & $13 \cdot 12$ & $60 \cdot 79$ & $26 \cdot 24$ \\
\hline \multicolumn{10}{|l|}{ Place of residence } \\
\hline Urban & $37 \cdot 95$ & $32 \cdot 82$ & $29 \cdot 23$ & $47 \cdot 69$ & $19 \cdot 49$ & $32 \cdot 82$ & $7 \cdot 69$ & $53 \cdot 33$ & $38 \cdot 98^{\star \star}$ \\
\hline Semi-urban & $33 \cdot 33$ & $34 \cdot 85$ & $31 \cdot 82$ & 43.94 & $15 \cdot 15$ & $40 \cdot 91$ & $18 \cdot 18$ & $54 \cdot 55$ & $27 \cdot 27$ \\
\hline Rural & $34 \cdot 24$ & $32 \cdot 54$ & $33 \cdot 32$ & $43 \cdot 39$ & $18 \cdot 64$ & $37 \cdot 97$ & $21 \cdot 02$ & $68 \cdot 81$ & $10 \cdot 17$ \\
\hline \multicolumn{10}{|l|}{ School enrolment } \\
\hline Dropout & $32 \cdot 37$ & $34 \cdot 10$ & 33.53 & $41 \cdot 04$ & $20 \cdot 81$ & $38 \cdot 15$ & $26 \cdot 59$ & $63 \cdot 58$ & $9 \cdot 83^{* *}$ \\
\hline Currently enroled & $36 \cdot 65$ & $32 \cdot 46$ & $30 \cdot 89$ & $46 \cdot 86$ & $17 \cdot 54$ & $35 \cdot 60$ & $11 \cdot 26$ & $60 \cdot 73$ & $28 \cdot 01$ \\
\hline \multicolumn{10}{|l|}{ Monthly expenditure } \\
\hline$\leq 2000 \mathrm{Rs}$ & $30 \cdot 40$ & $34 \cdot 80$ & $34 \cdot 80^{\star *}$ & $44 \cdot 40$ & $18 \cdot 80$ & $36 \cdot 80$ & $23 \cdot 60$ & $62 \cdot 80$ & $13 \cdot 60^{\star *}$ \\
\hline 2001-5000 Rs & $43 \cdot 40$ & $30 \cdot 82$ & $25 \cdot 78$ & $50 \cdot 94$ & $15 \cdot 74$ & $33 \cdot 32$ & 11.95 & $63 \cdot 52$ & $24 \cdot 53$ \\
\hline $5001-8000 \mathrm{Rs}$ & $39 \cdot 29$ & $39 \cdot 29$ & $21 \cdot 42$ & $41 \cdot 67$ & $19 \cdot 05$ & $39 \cdot 28$ & $9 \cdot 52$ & $65 \cdot 48$ & $25 \cdot 00$ \\
\hline$>8000 \mathrm{Rs}$ & 29.03 & $22 \cdot 58$ & $48 \cdot 39$ & $37 \cdot 10$ & $24 \cdot 19$ & $38 \cdot 71$ & $4 \cdot 84$ & $46 \cdot 77$ & $48 \cdot 39$ \\
\hline Dissatisfied with body weight & $14 \cdot 71$ & $58 \cdot 33$ & $26 \cdot 69$ & $41 \cdot 67$ & $17 \cdot 16$ & $41 \cdot 18$ & $37 \cdot 25$ & $33 \cdot 33$ & $29 \cdot 41$ \\
\hline Urge for dieting & $7 \cdot 92$ & $59 \cdot 41$ & $32 \cdot 67^{\star *}$ & $42 \cdot 57$ & $18 \cdot 81$ & $38 \cdot 61$ & $50 \cdot 50$ & $29 \cdot 70$ & $19 \cdot 80^{\star *}$ \\
\hline
\end{tabular}

*Significant at 0.05 level; **significant at 0.01 level.

suburban and rural counterparts with respect to certain dietary behaviours. But interestingly, these urban girls outnumbered the other two groups of girls in following a weight reduction diet. These girls, however, reporting to be on a weight reduction diet actually skipped their meals or consumed snacks (84\%) in place of normal meals (not shown in tables). Significant differences in perceptions of their own body weight and shape among girls of different residential areas were noticed.

Table 4 shows a positive relationship between expressed dissatisfaction over body weight and an urge for dieting among these girls with specific anthropometric measures. The participants who were dissatisfied with their body weight showed significantly higher mean values for body weight, BMI, waist circumference, hip circumference and summation of skinfold thickness compared to those who were not dissatisfied. Again, the participants who reported an urge for dieting showed significantly higher mean values for all the above-mentioned anthropometric measures as well as with mid-upper-arm circumference.

Interestingly, a majority ( $84 \%$ ) of the participants who expressed their dissatisfaction over body weight showed normal BMI. Similarly, a majority (81\%) of the participants who reported an urge for dieting were categorized as having a normal BMI (data have not been shown in tables) compared to those who showed no urge, and the difference was significant. Thus, actual BMI categorization was not related to the desired diet. 
Table 3 Dietary behaviour and weight concerns (\%) among participants according to place of residence

\begin{tabular}{|c|c|c|c|c|c|}
\hline Variables & Rural (n 305) & Suburban $(n 76)$ & Urban ( $n$ 196) & $x^{2}$ & Total $(n 577)$ \\
\hline \multicolumn{6}{|l|}{ Number of meals per day } \\
\hline Two & $35 \cdot 37$ & $36 \cdot 36$ & $19 \cdot 07$ & \multirow[t]{3}{*}{$18 \cdot 56^{\star \star}$} & $29 \cdot 84$ \\
\hline Three & $56 \cdot 18$ & $62 \cdot 12$ & $73 \cdot 20$ & & $64 \cdot 56$ \\
\hline More than three & $5 \cdot 44$ & $1 \cdot 52$ & $7 \cdot 73$ & & $5 \cdot 79$ \\
\hline \multicolumn{6}{|c|}{ Frequency of taking meals outside the home } \\
\hline Every day & $2 \cdot 72$ & $7 \cdot 58$ & $28 \cdot 35$ & \multirow[t]{4}{*}{$15 \cdot 44^{\star \star}$} & $12 \cdot 30$ \\
\hline Once per week & $13 \cdot 61$ & $28 \cdot 79$ & $36 \cdot 60$ & & $23 \cdot 51$ \\
\hline Once per month & $40 \cdot 82$ & $53 \cdot 03$ & $15 \cdot 98$ & & $33 \cdot 63$ \\
\hline Less than once a month & $42 \cdot 86$ & $10 \cdot 61$ & $19 \cdot 07$ & & $30 \cdot 74$ \\
\hline \multicolumn{6}{|l|}{ On weight reduction diet } \\
\hline No & $96 \cdot 91$ & $98 \cdot 48$ & $92 \cdot 18$ & \multirow[t]{2}{*}{$7 \cdot 33^{\star}$} & $94 \cdot 76$ \\
\hline Yes & 3.09 & $1 \cdot 52$ & $7 \cdot 82$ & & $5 \cdot 42$ \\
\hline \multicolumn{6}{|l|}{ Dissatisfied with body weight } \\
\hline No & $70 \cdot 82$ & $63 \cdot 16$ & $53 \cdot 06$ & \multirow[t]{2}{*}{$16 \cdot 30^{\star \star}$} & $63 \cdot 78$ \\
\hline Yes & $29 \cdot 18$ & $36 \cdot 84$ & $46 \cdot 94$ & & $36 \cdot 22$ \\
\hline \multicolumn{6}{|l|}{ Urge for dieting } \\
\hline No & $83 \cdot 28$ & $81 \cdot 58$ & $73 \cdot 98$ & \multirow{2}{*}{$6 \cdot 58^{\star}$} & $79 \cdot 90$ \\
\hline Yes & $16 \cdot 72$ & $18 \cdot 42$ & $26 \cdot 02$ & & $20 \cdot 10$ \\
\hline
\end{tabular}

${ }^{\star} P$ value $<0.05$ level; ${ }^{\star \star} P$ value $<0.01$ level.

Table 4 Anthropometric measures associated with dissatisfaction over body weight and urge for dieting

\begin{tabular}{|c|c|c|c|c|c|c|}
\hline \multirow[b]{2}{*}{ Parameters } & \multicolumn{3}{|c|}{ Dissatisfied with body weight } & \multicolumn{3}{|c|}{ Urge for dieting } \\
\hline & No $(n 365)$ & Yes ( $n$ 212) & $t$ value & No $(n$ 472) & Yes $(n$ 105) & $t$ value \\
\hline Weight (kg) & $47 \cdot 27$ & $48 \cdot 82$ & $2 \cdot 69^{\star *}$ & $46 \cdot 92$ & $20 \cdot 71$ & $7 \cdot 36^{\star \star}$ \\
\hline $\operatorname{BMI}\left(\mathrm{kg} / \mathrm{m}^{2}\right)$ & $20 \cdot 81$ & $21 \cdot 45$ & $2 \cdot 75^{\star \star}$ & $20 \cdot 71$ & 22.56 & $6 \cdot 54^{\star \star}$ \\
\hline WC $(\mathrm{cm})$ & $68 \cdot 25$ & $69 \cdot 86$ & $2 \cdot 67^{\star *}$ & 68.01 & 72.59 & $6 \cdot 23^{\star \star}$ \\
\hline $\mathrm{HC}$ & $86 \cdot 88$ & 88.09 & $2 \cdot 51^{*}$ & $86 \cdot 75$ & $89 \cdot 98$ & $5 \cdot 45^{\star \star}$ \\
\hline MUAC & $21 \cdot 40$ & $21 \cdot 71$ & $1 \cdot 80$ & $21 \cdot 28$ & $22 \cdot 59$ & $6 \cdot 39^{\star \star}$ \\
\hline SSF & $39 \cdot 01$ & $42 \cdot 85$ & $3 \cdot 36^{\star \star}$ & $38 \cdot 78$ & $47 \cdot 85$ & $6 \cdot 49^{\star \star}$ \\
\hline
\end{tabular}

WC, waist circumference; HC, hip circumference; MUAC, mid-upper-arm circumference; SSF, sum of skinfold thicknesses.

${ }^{\star} P$ value $<0.05$ level; ${ }^{\star \star} P$ value $<0.01$ level.

Place of residence and monthly family expenditure showed a significant association with an expressed feeling of dissatisfaction with body weight (Table 5). The participants who were dissatisfied with their body weight were about five times more likely to show a perceived desire to diet. Girls belonging to families with the highest monthly expenditure were about two times more likely to express their dissatisfaction over body weight compared to girls of families with the lowest monthly expenditure ( $O R=1.96)$.

While controlling for the sociodemographic factors, the relationship of BMI remained significant only with their reported urge for dieting and not with their reported feeling of dissatisfaction over body weight.

\section{Discussion}

The findings of the present study show that the dietary patterns among the girls are largely associated with their sociodemographic characteristics. Most of the girls in this group of adolescents, irrespective of their residential location, reported dissatisfaction with their body weight, leading to a perceived need for dietary modifications and/or dieting. Dissatisfaction over body weight and perceived need to diet among the girls were found to be directly associated with adiposity measures like BMI and waist circumference even when these measures were found to be within the normal range in most of the girls.

Selection and consumption patterns of different food items revealed the girls' intention to change their body shape and size, but by using potentially unhealthy measures. Instead of staple food, their regular meal included fruits only and they tended to prefer snacking between meals and reducing the quantity and variety of foods taken during main meals. Many urban girls showed a perceived need to diet but at the same time they consumed more than three meals per day and were more likely to have meals outside the home. In addition, the urban girls consumed significantly less than the other two groups. The difference in consumption patterns across socio-economic groups indicates a shift from traditional to non-traditional patterns. A positive association between the consumption of snacks and sugar-sweetened drinks and socio-economic status indicated that the girls from well-off urban families tended to consume more fast foods in place of major meals, which may contribute to the development of eating disorders and potential health consequences ${ }^{(5)}$. This could also be a risk indicator for the development of eating disorders such as anorexia nervosa and bulimia nervosa and may have serious health consequences. 
Table 5 Results of logistic regression for body weight concern (dissatisfied $v$. satisfied), dieting behaviour (urge for dieting $v$. no urge for dieting) among participants in relation to their sociodemographic characteristics and BMI

\begin{tabular}{|c|c|c|c|c|}
\hline \multirow[b]{2}{*}{ Variables } & \multicolumn{2}{|c|}{ Dissatisfied with body weight } & \multicolumn{2}{|c|}{ Urged for dieting } \\
\hline & OR & $95 \% \mathrm{Cl}$ & OR & $95 \% \mathrm{Cl}$ \\
\hline \multicolumn{5}{|l|}{ Age group } \\
\hline Younger adolescents & $1 \cdot 00$ & Ref. & $1 \cdot 00$ & Ref. \\
\hline Older adolescents & 0.99 & $0 \cdot 67,1 \cdot 45$ & $1 \cdot 22$ & $0 \cdot 74,2 \cdot 02$ \\
\hline \multicolumn{5}{|l|}{ Marital status } \\
\hline Unmarried & $1 \cdot 00$ & Ref. & $1 \cdot 00$ & Ref. \\
\hline Married & 0.85 & $0.51,1.42$ & $0 \cdot 37^{\star \star}$ & $0.24,0.97$ \\
\hline \multicolumn{5}{|l|}{ Place of residence } \\
\hline Rural & $1 \cdot 00$ & Ref. & $1 \cdot 00$ & Ref. \\
\hline Suburban & $1 \cdot 28$ & $0.46,1 \cdot 82$ & $1 \cdot 12$ & $0.48,2.59$ \\
\hline Urban & $1 \cdot 56^{*}$ & $1 \cdot 09,2 \cdot 34$ & $1 \cdot 93^{*}$ & $1 \cdot 23,2 \cdot 48$ \\
\hline \multicolumn{5}{|c|}{ Monthly expenditure of the family } \\
\hline$\leq 2000$ Rs & $1 \cdot 00$ & Ref. & $1 \cdot 00$ & Ref. \\
\hline $2001-5000 \mathrm{Rs}$ & $1 \cdot 36$ & $0 \cdot 71,2 \cdot 61$ & $1 \cdot 27$ & $0 \cdot 63,1 \cdot 85$ \\
\hline $5001-8000$ Rs & $1 \cdot 65$ & $1 \cdot 01,2 \cdot 73$ & $1 \cdot 31$ & $0 \cdot 52,2 \cdot 14$ \\
\hline$>8000 \mathrm{Rs}$ & $1 \cdot 96^{*}$ & $1 \cdot 29,3 \cdot 69$ & $2 \cdot 15^{\star}$ & $1 \cdot 41,3.58$ \\
\hline BMI $\left(\mathrm{kg} / \mathrm{m}^{2}\right)$ & $1 \cdot 04$ & $0.97,1 \cdot 12$ & $1 \cdot 28^{\star \star}$ & $1 \cdot 17,1 \cdot 40$ \\
\hline \multicolumn{5}{|c|}{ Dissatisfied with body weight } \\
\hline No & $\mathrm{NI}$ & $\mathrm{NI}$ & $1 \cdot 00$ & Ref. \\
\hline Yes & & & $5 \cdot 12^{\star \star}$ & $3 \cdot 10,8 \cdot 45$ \\
\hline \multicolumn{5}{|l|}{ Urge for dieting } \\
\hline No & $1 \cdot 00$ & Ref. & $\mathrm{NI}$ & $\mathrm{NI}$ \\
\hline Yes & $5 \cdot 22^{\star *}$ & $3 \cdot 17,8 \cdot 61$ & & \\
\hline
\end{tabular}

Ref., reference category; $\mathrm{NI}$, not included.

${ }^{*}$ Significant at 0.05 level; ${ }^{* *}$ significant at 0.01 level.

The present study also noted that a large number of girls who were dissatisfied with their body weight and perceived the need to diet remained within the normal range of BMI. The reason behind the eagerness to reduce body weight could be the result of societal pressure to be thin or any other factors that remain beyond the scope of the present study.

After controlling for other socio-economic variables, the effect of age was not found to be significant in logistic regression analysis. This finding is consistent with the results of several other community-based studies, which suggest that weight and shape concerns develop through adolescence and become more pronounced by late adolescence $^{(26,27)}$

\section{Strengths and limitations}

The present study adds to the existing literature by identifying dietary patterns and weight concerns among adolescent girls in an under-studied population group. An additional strength of the present study is its populationbased sample, which allowed for more generalization than clinical samples or convenience samples recruited for the purpose of examining weight-related issues. The inclusion of anthropometric measures is also another strength of the study, as most school-based studies on youth collect only self-reported height and weight.

In spite of the above strengths, the results of the present study should also be viewed as having limitations. Lack of adjustment of the dietary patterns for energy intake is one potential limitation of our study, because it lacks portion size data in the FFQ and also the measurement of physical activity of the study participants. This prevents us from assessing dietary under-reporting, particularly among those with a higher $\mathrm{BMI}^{(28)}$. Moreover, the cross-sectional nature of the study does not allow for the examination of changes in dietary behaviours and also prevents us from determining a cause-effect relationship.

\section{Conclusion}

The present study suggests a widespread sense of dissatisfaction with body weight and shape among both normal and overweight girls, which may lead to unnecessary food restraints and other unhealthy weight control practices among them. There are reasons for concern if non-overweight girls are trying to lose weight and if unhealthy weight control behaviours prevail among adolescents, regardless of their actual weight status. Educating the adolescents about what constitutes healthy weight and diet, healthy growth and physical maturation will help them understand the correct balance between energy intake and physical activity.

\section{Acknowledgements}

This research was supported by a grant from the Indian Statistical Institute. The authors declare that they have no conflict regarding this manuscript and have had no involvements that might raise the question of bias in the work reported. Both the authors were involved in the set-up of the study including data collection and writing 
of the manuscript. The authors are most thankful to the study participants and their parents for unhesitant support to complete the study. They expressed their gratitude to the Chief Medical Officers of all four districts of the state for providing advice and support in developing questionnaires. Dr Sharon R. Williams of Purdue University is thankfully acknowledged for improving the manuscript.

\section{References}

1. Neumark-Sztainer D \& Hannan PJ (2002) Weight-related concerns and behaviors among overweight and nonoverweight adolescents. Arch Pediatr Adolesc Med 156, 171-178.

2. Clay D, Vignoles VL \& Dittmar H (2005) Body image and self-esteem among adolescent girls: testing the influence of sociocultural factors. J Res Adolesc 15, 451-477.

3. Field AE, Austin SB, Striegel-Moore R et al. (2005) Weight concerns and weight control behaviors of adolescents and their mothers. Arch Pediatr Adolesc Med 159, 1121-1126.

4. Plotnikoff RC, Bercovitz K, Rhodes RE et al. (2007) Testing a conceptual model related to weight perception, physical activity and smoking in adolescents. Health Educ Res $\mathbf{2 2}$, 192-202.

5. Gowers SG \& Shore A (2001) Development of weight and shape concerns in the aetiology of eating disorders. $\mathrm{Br} J$ Psychiatry 179, 236-242.

6. Vemuri M \& Steiner H (2007) Historical and current conceptualizations of eating disorders: a developmental perspective. In Eating Disorders in Children and Adolescents, pp. 3-18 [T Jaffa and B McDermott, editors]. Cambridge: Cambridge University Press.

7. Holt KE \& Riccidelli LA (2008) Weight concerns among elementary school children: a review of preventive programs. Body Image 5, 233-243.

8. Riccidelli LA, McCabe MP, Lillis J et al. (2006) A longitudinal investigation of the development of weight and muscle concerns among preadolescent boys. J Youth Adolesc 35, 168-178.

9. Field AE, Camargo CA Jr, Taylor CB et al. (2001) Exposure to the mass media, body shape concerns and use of supplements to improve weight and shape among male and female adolescents. Pediatrics 107, 54-60.

10. Gazanniga JM \& Burns TL (1993) Relationship between diet composition and body fatness, with adjustment for resting energy expenditure and physical activity, in preadolescent children. Am J Clin Nutr 52, 421-425.

11. McGolin AF, Livingstone MB, Greene LC et al. (2002) Energy and fat intake in obese and lean children at varying risk of obesity. Int J Obes 26, 200-207.

12. Steinhausen HC (2002) The outcome of anorexia nervosa in the 20th century. Am J Psychiatry 159, 1284-1293.
13. Escobar-Chaves SL, Tortolero SR, Markham CM et al. (2005) Impact of media on adolescent sexual attitudes and behaviours. Pediatrics 116, 303-326.

14. Kant AK (2004) Dietary patterns and health outcomes. J Am Diet Assoc 104, 615-635.

15. Wertheim EH, Paxton SJ, Schutz HK et al. (1997) Why do adolescent watch their weight? An interview study examining socio-cultural pressure to be thin. J Psychosom Res $\mathbf{4 2}$, 345-355.

16. Schur EA, Sanders M \& Steiner H (2000) Body dissatisfaction and dieting in young children. Int J Eat Disord 27, 74-82.

17. Neumark-Sztainer D, Jeffery RW \& French SA (1997) Self reported dieting: How should we ask? What does it mean? Associations between dieting and reported energy intake. Int J Eat Disord 22, 437-449.

18. Chug R \& Puri S (2001) Affluent adolescent girls of Delhi: eating and weight concerns. BrJ Nutr 86, 535-542.

19. Sadana B, Khanna M \& Mann SK (1997) Consumption patterns of fast foods among teenagers. Appl Nutr 22, 14-17.

20. Stang J \& Story M (editors) (2005) Body image and adolescents. In Guidelines for Adolescent Nutrition Services. Minneapolis, MN: Center for Leadership, Education and Training in Maternal and Child Nutrition, Division of Epidemiology and Community Health, School of Public Health, University of Minnesota.

21. Tamang JP (1998) Indigenous fermented foods of the Sikkim Himalaya: a socio-economic study. In Sikkim: Perspectives for Planning and Development, pp. 513-524 [SC Rai, RC Sundriyal and E Sharma, editors]. Sikkim: Sikkim Science Society.

22. Lohman TG, Roche AF \& Martorell R (1988) Anthropometric Standardization Reference Manual. Champaign, IL: Human Kinetics Books.

23. Hu FB (2002) Dietary pattern analysis: a new direction in nutritional epidemiology. Curr Opin Lipidol 13, 3-9.

24. Schulze MB, Hoffmann K, Korke A et al. (2003) An approach to construct simplified measures of dietary patterns form exploratory factor analysis. Br J Nutr 89, 409-418.

25. McNaughton SA, Ball K, Mishra GD et al. (2008) Dietary patterns of adolescents and risk of obesity and hypertension. J Nutr 138, 364-370.

26. Russell GFM (1992) Anorexia nervosa of early onset and its impact on puberty. In Feeding Problems and Eating Disorders in Children and Adolescents, pp. 85-111 [PJ Cooper and A Stein, editors]. New York: Harwood Academic Publishers.

27. Baker D, Sivyer R \& Towell $T$ (1998) Body image dissatisfaction and eating attitudes in visually impaired women. Int J Eat Disord 24, 319-322.

28. Chung PCH, Ip PLS, Lam ST et al. (2007) A study on body weight perception and weight control behaviours among adolescents in Hong Kong. Hong Kong Med J 13, $16-21$. 